\title{
DE UTOPÍAS Y DESENGAÑOS: LA NOVELÍSTICA DIVISIONARIA DE RODRIGO ROYO
}

Of Utopias and Disillusion: Rodrigo Royo's Divisionary Novels

\author{
VALERIA POSSI \\ INVESTIGADORA INDEPENDIENTE (ITALIA) \\ vlr.possi@gmail.com http://orcid.org/0000-0003-1507-2392
}

RECIBIDO: 1 DE OCTUBRE DE 2018

ACEPTADO: 19 DE NOVIEMBRE DE 2018

RESUMEN: El artículo estudia las novelas de tema divisionario del autor Rodrigo Royo, veterano de la División Azul: ;Guerra! Historia de la vida de Luis Pablos (1944); El sol y la nieve (1956); y El Sepulturero (1976). El análisis se centra en el paso del idealismo falangista al desencanto por cómo se refleja en la novelización de la experiencia guerrera en el Frente Oriental. Específicamente, el estudio se focaliza en los cambios ocurridos en la caracterización de los protagonistas de las obras: Luis Pablos, el héroe falangista arquetípico de ¡Guerra! (1944), cuya heroicidad se fundamenta en el espíritu guerrero, la entrega al ideal y el desprecio a los peligros y la muerte; José Luis, el protagonista de El sol y la nieve (1956), un héroe todavía apegado a los dogmas del falangismo, pero definido por sus cualidades espirituales -la solidaridad, el honor, la rectitud moral-; y finalmente Julián Roviera, el héroe trágico de El Sepulturero (1976), que hace de su derrota vital, política e histórica la clave de su victoria moral.

PALABRAS CLAVE: División Azul, falangismo, idealismo, desencanto, héroe.

ABSTRACT: This article analyses the three divisionary novels by Rodrigo Royo, veteran of the Spanish Blue Division: ;Guerra! Historia de la vida de Luis Pablos (1944); El sol y la nieve (1956); and El Sepulturero (1976). I investigate the shift from Falangist idealism to disillusion and its reflection in the novelization of the war experience in the Eastern Front. Specifically, I focus on the changes that the characterization of the figure of the hero suffers on these works: Luis Pablos, the archetypal Falangist hero of ;Guerra! (1944), whose heroism is based on his warrior spirit, his idealism and the contempt for danger and death; José Luis, the protagonist of El sol y la nieve (1956), a hero which is still faithful to the dogmas of Falangism, but who is defined by his spiritual values -solidarity, honour and moral rectitude-; and finally Julián Rovira, the tragic hero of El Sepulturero (1976), who change his vital, politic and historical defeat into the key of his moral victory.

KeYwords: Blue Division; Falangism; Idealism; Disillusion; Hero.

\section{INTRODUCCIÓN}


La novelística sobre la División Azul escrita por los veteranos de guerra de ideología y militancia falangista se puede dividir, teóricamente, en dos etapas, cada una de ellas definida por unos rasgos comunes. Así, encontramos un primer grupo de novelas, escritas entre los años 40 y la mitad de los 50, que se definen por su marcado idealismo, reflejándose de forma preclara en la novelización de los acontecimientos bélicos en el Frente del Este durante la Segunda Guerra Mundial. Entre los hitos que marcan estas primeras novelas cabe destacar el lirismo que envuelve su prosa; la presencia manifiesta de consignas políticas y retóricas descendientes del marco ideológico de la Falange joseantoniana; una representación grandilocuente y ampulosa de la guerra; el ensalzamiento de la violencia, la masculinidad y la juventud; y finalmente, el culto al héroe y a la muerte (Possi, 2017: 250). Ejemplares, en este sentido, son Campaña de invierno (1943) de Enrique Errando Vilar; ;Guerra! Historia de la vida de Luis Pablos (1944) de Rodrigo Royo; Canción de invierno en el Este (1945) de José Luis Gómez Tello; Ida y vuelta (1946) de Antonio José Hernández Navarro; 4 infantes 3 luceros (1949) de Jaime Farré Albiñana; y Rusia no es cuestión de un día (1954) de Juan Eugenio Blanco.

Por otro lado, hay un segundo grupo de obras que incluye las novelas publicadas a partir de la segunda mitad de los años 50 hasta entrados los 70. Entre sus características sobresale, a nivel ideológico, el surgimiento de una visión del mundo influida por el desencanto; mientras que, a nivel estético y discursivo, semejantes relatos se alejan del imaginario lírico y épico, propio del discurso del falangismo primigenio, para plasmar la realidad de la guerra a partir de las directrices del realismo tremendista, y proporcionar la revisión de esos tópicos que fundamentaban la narrativa precedente. Lo que cambia es ante todo la percepción de la guerra misma, pues esta ya no se ve como una necesidad histórica y moral sino como un estado de terror y barbarie (Paniagua, 1961: 129). De ahí que, despojada de su halo mítico y artificioso, estas novelas se centren en los aspectos más crudos y dramáticos de las circunstancias bélicas, en su dimensión catastrófica y sus adversidades (Núñez Seixas, 2016: 394). Entre estas obras destacan División 250 (1954) y Camaradas 74 (1975) de Tomás Salvador; El soly la nieve (1956) y El Sepulturero (1976) de Rodrigo Royo; Algunos no hemos muerto (1957) de Carlos María Ydígoras; y finalmente, Los hombres se matan asi (1961) de Eleuterio Paniagua ${ }^{1}$.

Ya que autores como Tomás Salvador y Rodrigo Royo escribieron respectivamente dos y tres novelas de temática divisionaria, el análisis de sus obras es particularmente útil a la hora de estudiar tanto los cambios en la representación de la guerra en la Unión Soviética como la evolución personal e ideológica de estos autores y su inconformidad para con el cambio del régimen franquista en la posguerra mundial, sobre todo en lo que concierne al proceso de "desfascistización" de la España dictatorial, a raíz del cual Falange fue prácticamente excluida de los centros del poder (Bernecker, 1998: 29, 34-35; Böcker, 1998: 16; Penella, 2006: 419; Ruiz Bautista, 2005: 19; Wahnón, 1998: 12); y del progresivo silenciamiento de la memoria de la División Azul dentro del discurso hegemónico del régimen.

\footnotetext{
1 Es menester precisar que algunas de las obras mencionadas siguen perpetuando unos cuantos tópicos de las primeras novelas divisionarias, proporcionando aún muestras de fidelidad al ideario falangista primigenio, y situándose en una fase intermedia del paso entre el idealismo fanático y exacerbado, y el desencanto más adusto. Ejemplo de tal postura son El soly la nieve (1956) de Rodrigo Royo y División 250 (1954) de Tomás Salvador.
} 
Por estas razones, objeto del presente análisis serán las tres novelas de tema divisionario de Rodrigo Royo, quizá el escritor más idealista y politizado entre los veteranos falangistas, cuya trayectoria literaria está profundamente marcada por la amargura y la autocrítica (Caballero Jurado e Ibáñez Hernández, 1989: 116): ;Guerra! Historia de la vida de Luis Pablos, publicada en 1944 y extremadamente ortodoxa para con el ideario falangista; El sol y la nieve, de 1956, de tonos más íntimos y reflexivos; y finalmente, El Sepulturero, de 1976, en la que el recorrido del escritor desde los sueños utópicos de la juventud hasta los desengaños de la madurez llega a su cumbre. El análisis comparativo de las novelas de Rodrigo Royo enseña abiertamente los cambios ocurridos en el discurso divisionario acerca de los argumentos mencionados con anterioridad, sobre todo en lo que concierne a la reflexión acerca de los ideales, la influencia y la praxis política del falangismo dentro del régimen franquista, y la caracterización del héroe. Además, hay que alegar que la "trilogía divisionaria" de Rodrigo Royo es emblemática de la evolución política e ideológica de los falangistas radicales. De hecho, la coincidencia entre las posturas del escritor y las expresadas por sus narradores y personajes es avalada por unos rasgos autobiográficos -O autoficticios ante litteram - compartidos por los tres protagonistas de las novelas y el autor empírico, lo que consolida la hipótesis de trabajo que nos guía, esto es: que, pese a la naturaleza ficcional de los textos analizados, estos reflejan fehacientemente los sentimientos de una entera generación de militantes y luchadores, quienes finalmente vieron frustrados sus anhelos revolucionarios ${ }^{2}$.

\section{¡GUERRA! Historla DE LA VIDA DE LUIS PABLOS (1944): EL HÉroE GUERRERO}

Como ya se ha puesto de manifiesto, el mito del héroe es central tanto dentro de la literatura fascista en general como de la divisionaria en particular (Possi, 2017: 233; Prill, 1998: 170). En las novelas divisionarias de la primera etapa, los protagonistas se suelen representar a partir de unas coordenadas ideológicas que convierten el mito del héroe en un tópico específico suyo, en cuya imagen se condensan los siguientes rasgos caracterizadores: la entrega desinteresada al ideal, el desprecio de los peligros, los deseos de gloria, el ensalzamiento de la violencia, y, finalmente, los ecos imperiales que insertan sus gestas dentro de la tradición gloriosa de España (Albert, 2003: 267; Jesi, 2015: 62).

\footnotetext{
${ }^{2}$ Recordemos que la autoficción establece una "correspondencia referencial entre el plano del enunciado y el de la enunciación, entre el protagonista y su autor", creando "un original espacio autobiográfico y novelesco en el que se [...] mezclan las fronteras entre lo real y lo inventado" (Alberca, 2007: 31-32). En este espacio se instala pues la parcial identidad que se da, en la trilogía divisionaria, entre el autor empírico y los protagonistas de sus novelas. Y estriba en la correspondencia entre las mutilaciones padecidas por Rodrigo Royo (Caballero Jurado e Ibáñez Hernández, 1989: 115-116; Mainer, 2008: 142) y las sufridas por los protagonistas de sus novelas. A los tres, el frío de la estepa rusa les provoca una congelación severa que se resuelve con amputaciones de diferente alcance en los pies (Royo, 1944: 15; Royo, 1956: 349) y en las manos (Royo, 1976: 38, 89). Además, los tres personajes pasan por los mismos hospitales, antes el de Grigorowo y finalmente el de Utorgosh (Royo, 1944: 194-196; Royo, 1956: 338-340; Royo, 1976: 89). También, como guiño textual postrero, Rodrigo Royo se inserta a sí mismo como personaje en la novela ;Guerra! (1944), en la que está ingresado en el mismo hospital que Luis Pablos por haber sufrido congelación él también; lo que le permite, dentro de la ficción, hacerse con los diarios del compañero en el momento de su muerte y publicarlos después, en un juego o tópico metaliterario que establece una analogía entre el texto ficticio y el texto que el lector empírico está leyendo. Algo que, por otro lado, ya ocurría en el aparato paratextual que cierra la novela División 250 (1954) de Tomás Salvador (1954: 404, 407).
} 
La misma División Azul, en su conjunto, se reviste de rasgos míticos y heroicos (Núñez Seixas, 2005: 83), que permanecen invariados en las tres novelas de Rodrigo Royo; el desencanto creciente que se da en El sol y la nieve (1956) y El Sepulturero (1976) no llega a poner en entredicho el heroísmo que subyace a las hazañas divisionarias, porque la decepción de los veteranos de guerra tiene que ver con las circunstancias políticas de la España franquista después del final de la Segunda Guerra Mundial, y no con algún tipo de arrepentimiento por su enrolamiento o militancia falangista.

Así, en ¡Guerra! (1944), los divisionarios se comparan con los "caballeros diestros y corajudos" de "los mejores tiempos del emperador" Francisco I (Royo, 1944: 27-28); y los soldados españoles que marchan a la guerra contra la Unión Soviética son "los fuertes -de cuerpo y de espíritu-" (Royo, 1944: 31). Asimismo, en El sol y la nieve (1956) se afirma que los divisionarios llevan en su sangre "la misteriosa herencia de siglos y más siglos de tenacidad defensiva, [...] el espíritu inexpugnable, transmitido por vía de las generaciones, de tantos Saguntos, Numancias, Zaragozas y Alcázares” (Royo, 1956: 318); y se insiste en la representación de los voluntarios en el Frente del Este como homólogos contemporáneos de "los conquistadores españoles del Renacimiento" (Royo, 1956: 58). En El Sepulturero (1976) también, Julián Rovira declara ser descendiente de Hernán Cortés (Royo, 1976: 11), lo que confirma la importancia de este argumento y resalta la coherencia ideológica que se mantiene en las tres novelas con respecto a la interpretación de la gesta divisionaria, digna de insertarse "en la soleada y lírica ladera de la poesía y el quijotismo" (Royo, 1976: 83)³.

Lógicamente, en cuanto divisionarios, también los tres protagonistas de las novelas son representados como héroes, pero la naturaleza y esencia de su heroicidad es sometida a transformaciones radicales que dependen de la etapa en que las obras se sitúan, la del idealismo o la del desencanto. Luis Pablos, por ejemplo, es el divisionario arquetípico, cuya evolución y transformación final en héroe se encuentra en consonancia con la narración falangista de los orígenes. No solamente reúne en sí las virtudes del militante falangista entregado a la causa y apegado al ideal del monje-soldado -el entusiasmo, el fanatismo, la valentía, la abnegación, la fe en los objetivos y el desprecio por lo material (Carbajosa y Carbajosa, 2003: 116; Di Febo, 1991: 205; Mainer, 2008: 174)-, sino que sus vivencias escenifican a la perfección el difícil camino que ha de seguir el falangista modélico para alcanzar el estilo o modo de ser que definen la esencia del Movimiento: el espíritu de sacrificio y de servicio, el ascetismo, y la vida entendida como milicia (Pemartín, 1949: 30; Primo de Rivera, 1939: 24; Primo de Rivera, 1940: 102). El protagonista de ¡Guerra! (1944) expresa, pues, el rechazo de la ideología y la literatura falangistas hacia la vida de los "burgueses chatos y apoltronados que padece España" (Royo, 1956: 71).

\footnotetext{
${ }^{3}$ Pese a reconocer, románticamente, la trascendencia de las hazañas divisionarias en lo que concierne a la ideológico, lo heroico y lo poético, el narrador de El Sepulturero (1976) enfatiza a la vez el lado quijotesco de la experiencia guerrera en la Unión Soviética, siendo consciente, como otros personajes, de la práctica inutilidad e inoperancia de la División Azul, tanto en el contexto de la Guerra Mundial como en el de la política interior española a la vuelta del frente (Royo, 1944: 121; Royo, 1976: 83). Sin embargo, "la aventura quijotesca de la División Azul” (Royo, 1956: 77) no se ve corrompida por su falta de utilidad; al revés, al igual que el héroe cervantino, es ensalzada hasta convertirse en el símbolo de la pureza de los grandes ideales, por los que hay que luchar, aunque sea desaforadamente y a contracorriente. Esto es lo que, finalmente, le otorga a la empresa divisionaria su significado profundo y metafísico, que no es afectado por las circunstancias políticas e históricas sucesivas a sus actuaciones bélicas.
} 
Como ya alegara Albert, lo que caracteriza a los héroes literarios falangistas es la rebelión a las categorías estéticas y éticas de las vanguardias, cuyos personajes reaccionaban a la crisis de la modernidad recluyéndose en una dimensión individualista marcada por el aburrimiento y la desesperación. El fascismo y Falange se presentan como un camino de redención a la bohemia, como una entidad que le otorga sentido, fin y contenido a esa vida burguesa definida por la desorientación y las quimeras (2007: 61, 67, 253). En conformidad con los dictámenes del falangismo radical, ese camino de perfección y redención pasa necesariamente por la experiencia bélica, puesto que la guerra, en los fascismos nacionales, era interpretada como una necesidad y un hecho moral, que purificaba la sociedad, garantizaba el crecimiento espiritual de los pueblos y los individuos y permitía el desarrollo de virtudes capitales como la disciplina, la obediencia y el coraje (Penella, 2006: 264; Zunino, 2013: 354-355)4.

Así, es el mismo Luis Pablos quien admite que, hasta el momento de enrolarse en la División Azul, su vida era "de una vulgaridad monótona: [...] era un muchacho atolondrado y romanticazo” (Royo, 1944: 17-18). El arrepentimiento por haber sido de inclinación soñadora y propensa a la cursilería se reitera en sendas ocasiones a lo largo de la narración, clasificando al hábito imaginativo de vicio (Royo, 1944: 26, 37, 66); y lamentando además el haber rendido culto a la vida acomodada, algo por lo que, después de haber conocido la realidad de la guerra, el personaje siente una honda vergüenza (Royo, 1944: 29).

De hecho, Luis Pablos no escatima en su relato esos episodios que muestran abiertamente sus deficiencias personales antes de convertirse en el arquetipo del héroe falangista. Los numerosos episodios de sus negligencias tienen amplia resonancia en la narración, desde la pérdida de unos cartuchos y el correaje hasta una violenta discusión con un superior, incluyendo también el haberse quedado dormido durante un turno nocturno de guardia (Royo, 1944: 100-105). No obstante, el acontecimiento más embarazoso en el que se ve involucrado Luis Pablos no tiene que ver con la experiencia castrense, sino con el abandono del joven a los placeres sensoriales, a los vicios de su vida estudiantil y burguesa. Una noche, el narrador se aleja del campamento con una mujer que le conduce a un prostíbulo, donde se acuesta con ella y se emborracha ${ }^{5}$. Allí conoce a otro divisionario, igual de ebrio que él, con quien decide irse al barrio judío para prenderle fuego; finalmente, los dos terminan agredidos y retenidos por un grupo de judíos. Al darse cuenta de que los dos militares no son alemanes sino españoles, los judíos les

\footnotetext{
${ }^{4}$ En una entrevista publicada en febrero de 1936, José Antonio Primo de Rivera afirma por ejemplo que "La guerra [...] es inalienable al hombre. [...] Es un elemento de progreso... ¡Es absolutamente necesaria!” (Trigo, 1936: 5).

${ }^{5}$ En el relato se sugiere también que la joven prostituta le contagia a Luis Pablos la sífilis (Royo, 1944: 68-69). Sin embargo, la prolepsis no se retoma en ningún momento de la narración, por lo que, pese a la insinuación, la bravuconada del protagonista no tiene en la historia otros efectos más que los que se comentan en el cuerpo del texto. También es posible que la enfermedad venérea de Luis Pablos entre dentro de esas "situaciones escabrosas" que el recopilador de sus memorias afirma haber suavizado en el momento de editarlas (Royo, 1944: 218).
} 
profesan simpatía y hasta cariño, y deciden devolver a Luis Pablos a su campamento, borracho y sin conocimiento (Royo, 1944: 77-82).

La sanción que le impone el capitán al narrador a raíz de ese percance es obviamente dura, y le castiga atándole un saco de arena a la espalda a lo largo de varios días. Luis Pablos, sintiéndose humillado por la imposición, medita vengarse violentamente; pero el discurso de su capitán al darse cuenta de la nueva insumisión del soldado, en el que le recuerda la dificultad que entrañan la obediencia y el servicio a la patria, opera una profunda transformación en el narrador, quien a partir de ese momento empieza a darse cuenta de cómo se acentúa en él el deseo de entregarse "a un ideal profundo", además de convencerse de la absoluta necesidad de "la ciega obediencia, contra la que siempre había guardado cierta prevención” (Royo, 1944: 88-89). La historia de Luis Pablos se convierte, pues, en una etopeya emblemática de "La transformación de un soñador despersonalizado y abúlico en revolucionario" (Albert, 2003: 325); y el narrador nos enseña su formación y aprendizaje, llegando a convertirse en un luchador ejemplar y en el arquetipo de esa juventud idealista forjada a través de una "vida intensa, dura, sencilla, llena de poesía" (Royo, 1944: 7) ${ }^{7}$.

Luis Pablos es, por lo tanto, un héroe de reminiscencias clásicas, habiendo luchado y triunfado sobre sus propias limitaciones, para llegar finalmente a un estado de gloria o perfección (Campbell, 2017: 35). Y, como todos los héroes, el sentido último de su vida se sella con la muerte, con el sacrificio supremo en pos del ideal (Campbell, 2017: 383; Prill, 1998: 171). No obstante, la muerte de Luis Pablos no es tan edificante como podría esperarse por el tono triunfalista y ortodoxo que domina la novela en su mayor parte, y por las alabanzas de corte irracionalista a la guerra, la violencia y la fuerza que se convierten en los reales leitmotive del relato.

Afirmamos esto porque Luis Pablos escribe sus memorias cuando está ingresado en el hospital y acaban de amputarle ambos pies (Royo, 1944: 15). Su muerte es, sin duda alguna, una muerte por el ideal; y aunque no tiene lugar físicamente en el frente, sí ocurre allí en la mente de Luis Pablos. Este, sumido en un delirio alucinatorio ante mortem, y creyendo estar en la batalla frente al enemigo, baja saltando de su cama con un rugido belicoso para enseguida caer de bruces al suelo, exánime, y comentando el narrador Rodrigo Royo -quien relata los momentos finales de la vida del personaje- que "Abril, en un Domingo de Ramos, tomó su vida, apretada aún y

\footnotetext{
${ }^{6}$ La reacción del grupo de judíos, quienes les perdonan la vida a los dos divisionarios solo por ser españoles, es un tópico difundido en la novelística divisionaria, en la que los autores intentan establecer una neta diferencia entre los alemanes y ellos mismos con respecto a las relaciones tanto con la población civil rusa como con los judíos de los guetos. Los testimonios ficticios y memorísticos acerca de la cuestión "se presentan [...] a través de un prisma monocolor. No sólo habría existido buena convivencia, sino además pleno respeto, aprecio y solidaridad mutua" (Núñez Seixas, 2016: 240).

${ }^{7}$ Es menester recordar el valor de la poesía en la doctrina primigenia de Falange. Primo de Rivera, por ejemplo, estaba convencido de que "A los pueblos no los han movido nunca más que los poetas" (1939: 25); así como Pemartín incide en que "La Moral de la Falange [...] abarca dos Preceptos Fundamentales: el Precepto de Servicio y el de Imperativo Poético", siendo además Falange "un Movimiento que nunca puede olvidar la aspiración poética, que busca en la Poesía, no sugestivos adornos circunstanciales, sino su norma constante de conducta" (1949: 26, 29). La centralidad del elemento poético en el entramado ideológico y retórico de la Falange es una de las muestras más evidentes de su tendencia irracionalista. El llamamiento de la juventud a la acción se realizaba a través de discursos recargados de emotividad y entusiasmo, que sustituían la racionalidad a la vez que enmascaraban en un aura sentimentalista el vacío que caracterizaba a su programa político (Cano Ballesta, 1994: 29-32; Martín, 1978: 127).
} 
olorosa, como un capullo, y la hizo germinar en una rosa de heroísmo" (Royo, 1944: 222) ${ }^{8}$. Es evidente, pues, que el fallecimiento del protagonista de la novela es la confirmación concluyente de su condición heroica; a la vez que le otorga a la figura Luis Pablos un poder ejemplarizante y propagandístico.

Sin embargo, hay unos pasajes que suponen una importante incongruencia dentro del planteamiento de la novela, en específico, en el apartado titulado "Delirio" (Royo, 1944: 211-213), donde Luis Pablos refuta claramente todas sus afirmaciones anteriores acerca de la glorificación de la fuerza (Royo, 1944: 30-31, 44) y deplora la inutilidad del sacrificio, alegando finalmente que "Ya no creo en la idea, en el bello sentido de nuestro caminar, en el valor trascendente de nuestras acciones. Ya no creo en nada. Me parece que somos una colección de necios y de locos" (Royo, 1944: 212).

Las meditaciones conclusivas de las memorias del personaje, además de la explicación ininteligible y harto dudosa que ofrece quien las recopila para justificar esa retractación, parecen viciar el mensaje ideológico subyacente a la novela, así como mancillan la imagen heroica de Luis Pablos. A pesar de esto, el hecho de que esas aseveraciones encuentren cabida en los momentos finales de enajenación del personaje les resta veracidad. Es razonable afirmar, entonces, que la abjuración de los ideales del protagonista es una ulterior muestra de la grandiosidad del heroísmo de Luis Pablos, quien, pese a dudar en los momentos finales de su vida del ideal profesado, se entrega igualmente a la muerte. De esa forma, el triunfo de la Idea sobre el individuo es escenificado magistralmente, lo que confirma también el valor simbólico que adquieren los héroes falangistas en esta literatura, ya que la imagen del soldado que se construye en ella es claramente, "más que una realidad histórica, [...] una categoría estética cultural" (Pradera, 2014: 263).

EL SOL Y LA NIEVE (1956): EL HEROÍSMO ESPIRITUAL

De la misma manera heroica es caracterizado también José Luis, el protagonista de El soly la nieve (1956), pese a que este personaje no muere en el final de la novela, algo que se distancia parcialmente de la obra anterior, pero no del recorrido tópico de la aventura mitológica del héroe, que termina indistintamente con la muerte de este o con su retorno a la sociedad de partida. Por medio de la muerte o de la vuelta al lugar desde donde se había marchado, el héroe cumple con su misión, la de ofertar dones o bienes superiores a sus hermanos, que coinciden con "los medios para lograr la regeneración de su sociedad como un todo" (Campbell, 2017: 45, 53). Algo que,

\footnotetext{
${ }^{8}$ El paralelismo que se establece entre Cristo y el joven falangista es emblemático del mensaje último de la novela: Luis Pablos, como Jesús, se sacrifica por la redención de sus semejantes (Pérez Bowie, 1979: 14, 17; Prill, 1998: 171). Además, la referencia al Domingo de Ramos le otorga a la muerte del personaje otro valor añadido, el del sacrificio voluntario, sugiriendo que Luis Pablos sabe que va a morir y lo acepta con resignación, así como Jesús es consciente de que será crucificado en Jerusalén, y sin embargo acepta su destino porque su muerte garantizará la redención de los pecadores (Mt 16, 21-23). Para un análisis exhaustivo de la muerte del narrador Luis Pablos y su valor paradigmático como sacrificio último por el ideal véase Possi, 2017: 247-250.
} 
dentro de la cosmovisión falangista, puede identificarse con el surgimiento de la nueva España a través de la revolución nacionalsindicalista?

Los doce años transcurridos entre la publicación de ;Guerra! (1944) y la de El sol y la nieve (1956) hacen que en esta segunda novela el discurso doctrinario de Falange no sea tan acentuado y acrítico como en la primera. Los soldados divisionarios se siguen retratando con rasgos heroicos y sublimados, pero ya se va abriendo una brecha entre lo ideológico y la realidad recreada, desde la que brotan los primeros síntomas del desencanto que encontrarían su apogeo en la novela sucesiva, El Sepulturero (1976).

Con respecto al valor de los divisionarios y a su integridad moral se pueden tomar como ejemplo al protagonista, José Luis, y a otro soldado llamado Eugenio. Ambos personajes no son tan jóvenes como Luis Pablos, sino que rondan la treintena y ya tienen un recorrido bélico y político anterior al enrolamiento en la División Azul, siendo además hombres extremadamente formados y cultos. José Luis, por ejemplo, habla corrientemente español, francés y ruso; es doctor y abogado, y un intelectual de referencia entre las jerarquías de Falange, a la que se afilia a raíz de la Revolución de Asturias de 1934; finalmente, se presenta como uno de los jefes políticos más relevantes de su generación, habiendo sido oficial durante la Guerra Civil y ocupando posteriormente puestos de responsabilidad en el gobierno español (Royo, 1956: 52-55, 18). Pese a este currículo política e intelectualmente excelso, José Luis se alista en la División Azul como soldado raso; y pese a tener la posibilidad de solicitar una colocación nada peligrosa en la retaguardia en lugar que en el frente, renuncia a ella porque "en el frente, poseía una autoridad especial sobre sus camaradas, que él no cambiaría por ninguna retaguardia del mundo, mientras se tuviesen que seguir dirimiendo sobre el campo de batalla [...] cuestiones tan capitales como la existencia de Dios y la supervivencia de España" (Royo, 1956: 18). La nobleza de José Luis es ya perceptible en su biografía, en sus dotes políticas e intelectuales siempre acompañadas por la humildad, resaltada por su decisión de no aprovecharse de ninguna clase de privilegio consecuente con su estatus.

También el personaje Eugenio es tan reputado como José Luis. Como este, es doctor en Derecho y Filosofía y fue oficial condecorado en la Guerra Civil, llegando a desempeñar el cargo de gobernador de una provincia en la posguerra; y, al igual que este, ha rehusado de los posibles privilegios derivados de su autoridad y renombre para alistarse como simple guripa (Royo, 1956: 15, 34). Aun así, y siguiendo un lugar común muy difundido en la novelística divisionaria en su conjunto, los casos de José Luis y Eugenio no son particularmente señalados dentro del gremio divisionario, puesto que la División Azul "no era un Ejército regular, sino una división de

\footnotetext{
${ }^{9}$ De hecho, Luis Pablos afirma que "nuestra generación [...] está predestinada [...] a abrir en sus venas surtidores de sangre tibia y joven con vocación de fecundar la tierra para que brote el heroísmo como un bosque de gloria" (Royo, 1944: 206); mientras que José Luis, quien sobrevive a las mutilaciones, al recuperarse siente la urgencia de "volver a la gran batalla de la Historia, aunque no podría ser otra vez la misma batalla de las trincheras, porque con aquel pie cortado ya no volvería a ser nunca soldado de la fiel infantería. Pero seguiría militando igual en la trinchera del pensamiento y de la acción política. La experiencia de la guerra le había fortalecido y potenciado el alma” (Royo, 1956: 350). Luis Pablos, después de alcanzar la perfección heroica, muere y testifica con su sacrificio la superior bondad del ideal; en cambio, José Luis seguirá con su vida y volverá a España. La madurez ideológica y el crecimiento espiritual, que ha alcanzado gracias a su experiencia en la guerra, serán puestos al servicio de la sociedad, para la salvación de España, el cumplimiento de su destino universal, y el triunfo de la revolución falangista (Royo, 1956: 54, 361-362, 365).
} 
voluntarios, formada en su inmensa mayoría por hombres que tenían una visión clara del papel que ellos habían elegido representar por decisión libérrima" (Royo, 1956: 34). Sus integrantes, además, encarnan a la perfección el tópico literario de las armas y las letras, conformando una unidad más intelectual que militar en la que la mayoría de ellos "manejaban los cañones del 15,50 y los fusiles ametralladores con la misma facilidad con que recitaban de memoria los sonetos de Garcilaso" (Royo, 1956: 265). Es lícito pues afirmar que, también en la segunda novela de Rodrigo Royo, el imaginario de los divisionarios es conforme a la idealización del militante falangista arquetípico, cuya representación pivota en el valor, la fe en el ideal, la entrega a la causa, y unas virtudes derivadas de la fusión de elementos poéticos, religiosos y guerreros.

Aunque la División Azul es una unidad selecta por la distinción de sus integrantes, el desencanto que cunde entre los exdivisionarios conforme van pasando los años se evidencia en sus obras en las reflexiones de los narradores y protagonistas, o en las pláticas entre sus personajes ${ }^{10}$. Centrales, en este sentido, son la amargura y desconfianza de Eugenio, y ciertas dudas expresadas por José Luis en la narración.

Eugenio, a quien se tilda de "escéptico falangista" (Royo, 1956: 71), cuenta por ejemplo haberse alistado no "con la resolución de un predestinado" (Royo, 1944: 29), como ya hiciera Luis Pablos, sino "por asco, $[\ldots]$ porque después de tres años de lucha fratricida, de matarnos los unos a los otros, ahora volvemos otra vez a las andadas, y vienen los enemigos de siempre y nos arrebatan la bandera, y nos echan a un lado" (Royo, 1956: 37). La decepción de Eugenio para con

\footnotetext{
${ }^{10}$ Hay numerosas muestras de este desencanto que se apoderó de los divisionarios pertenecientes a la facción más radical de Falange, tanto en la novelística como en la narrativa referencial escritas por los veteranos de la Segunda Guerra Mundial. Un ejemplo de este sentimiento se encuentra en Los cuadernos de Rusia (1978) de Dionisio Ridruejo, en los que el autor, al explicar los motivos que le llevaron a alistarse en la División Azul, habla de "una crisis de inadaptación o de desencanto" y de la decepción, compartida con sus conmilitones -todos ellos "falangistas desilusionados"- para con "la España reaccionaria y «quietista» que se nos ha organizado. Inconformistas en suma” (Ridruejo, 2013: 55, 69). Y esto, pese a que Ridruejo fuese uno de los promotores de la intervención en la guerra al lado de la Alemania nazi, y uno de los fundadores de la División Azul.

Asimismo, hay evidencias parecidas también en mucha de la novelística divisionaria, donde son los mismos protagonistas de las obras los que enseñan en sus meditaciones esta actitud desencantada. Por ejemplo, en la novela Algunos no hemos muerto (1957) de Carlos María Ydígoras, el narrador escenifica una tertulia en el frente entre dos soldados, quienes, mostrando toda su reprobación hacia la España de la posguerra, afirman que "los derechoides" por los que ingenuamente lucharon durante la Guerra Civil, en un plazo máximo de diez años, ya se dedicarán tan solo "a hinchar sus estómagos de pulpo. [...] Empezarán a salir grupitos, sacará la garra la Banca, los terratenientes creerán que la guerra se hizo sólo para que pudiesen seguir explotando a los campesinos...”, concluyendo con amargura que "Nosotros sólo hemos hecho de sacos terreros. Los que de verdad sabían para qué se hacía la guerra se quedaban detrás. Verás qué poco tardan en ponerse en primera fila y borrar todo lo que huela a lo que nosotros queremos. ¡Diez años te doy de plazo! [...] Para entonces, si José Antonio levantase la cabeza la diñaría del susto" (Ydígoras, 1984: 54-55). Este ejemplo es solo uno de los incontables que se pueden rastrear en la novelística divisionaria del desencanto, en la que varios autores, en los apartados introductorios de sus obras, hablan abiertamente de las "muchas decepciones [que] han ocupado el lugar de los bríos de entonces", convirtiendo a los divisionarios en los integrantes de una "generación frustrada" (Salvador, 1954: 5-6). Sin embargo, y pese a las decepciones, estos novelistas afirman permanecer fieles a su ideario juvenil y a los "ideales que le[s] llevaron a Rusia con la División Azul [...] mientras ocupaban puestos privilegiados en las esferas del poder personas que, entonces, utilizaban aquellos ideales como escala de promoción personal y luego los han arrojado como lastre, del que mejor era olvidarse" (Ruiz Ayúcar, 1976: 9). En conclusión, la desilusión de los veteranos divisionarios desprende de toda la novelística escrita a partir de finales de los 50, aunque, como hemos mostrado brevemente, siempre se acompaña y se explica por la fidelidad a los ideales juveniles y en contra los traidores que hicieron la guerra para "arrimarse al brasero político y llenarse la tripa y olvidarse de lo que un día creyeron que eran” (Ydígoras, 1984: 55).
} 
la situación en la España de posguerra se debe pues, aparte de la conciencia de haber luchado y estar luchando para defender nuevamente los intereses de la burguesía y las clases acomodadas -“esa ralea de seres avaros y egoístas” (Royo, 1956: 80)-, a la sospecha que la División Azul está siendo utilizada por Franco para garantizar la neutralidad española en la Guerra Mundial, a la vez que para aparentar el saldo de las deudas contraídas con la Alemania nazi durante la Guerra Civil (Royo, 1956: 71, 77-78).

Las razones del desencanto de Eugenio son políticas, por lo que el personaje no puede rechazarlas sino, solamente, seguir luchando por sus ideales como "un sentimental estúpido, un romántico cursi, un imbécil" que "estaba dispuesto a morir de verdad porque todo esto le daba asco y le producía náuseas en el corazón y él lo que quería era morir cuanto antes y acabar de una vez" (Royo, 1956: 81); mientras que las dudas de José Luis abarcan una dimensión menos trascendental. Lo que le lleva al protagonista a la nostalgia por la vida en la paz, y al deseo de volver a ella mediante una imaginaria deserción, son argumentos triviales: el deseo de un baño caliente, de ropa limpia y despiojada, el encaprichamiento por una muchacha. Por esto, al contrario que Eugenio, José Luis puede fácilmente despachar esas sugestiones, haciendo hincapié en la fortaleza de su fe en los principios falangistas y en la misión histórica que cree estar cumpliendo (Royo, 1956: 34, 202) ${ }^{11}$.

No obstante, José Luis es representado por el narrador de la novela como un verdadero héroe, en lo marcial pero sobre todo en lo moral, como atestiguan dos episodios concretos en la narración. El primero tiene que ver con la aparición en la historia del hermano de José Luis, Santiago, un militante comunista que, después de haber combatido en el bando republicano durante la Guerra Civil, huye a la Unión Soviética, donde termina siendo el comisario político responsable de organizar las formaciones de partisanos que hostigan a la División Azul. Puesto que Santiago le salvó la vida a José Luis en la Guerra Civil, cuando el divisionario se entera de que detrás de la identidad ficticia del comisario Boris Protsenko se esconde su propio hermano es atormentado por resquemores y dudas. Por un lado, es consciente de que Santiago es un asesino y un criminal, además de ser un enemigo de España, por lo que su sentido del deber y sus principios le obligarían a desvelar a los mandos militares divisionarios el lugar donde está escondido, para que le detengan y le fusilen. Pero, por otro, su humanidad, su fidelidad a la familia y la deuda moral que José Luis siente que tiene con su hermano le instan a no denunciarlo. Su dilema, finalmente, se resuelve de la mejor forma, posibilitando que José Luis le pague su deuda a Santiago, sin por eso traicionar sus propios principios y sus deberes para con la División Azul. El protagonista encuentra una manera de hacerle llegar un mensaje a Santiago, en el que le

\footnotetext{
${ }^{11}$ En la novela se muestran también las debilidades de otros personajes, quienes pertenecen a las clases subalternas y no poseen el mismo rigor moral e ideológico y la misma erudición y sabiduría que José Luis y Eugenio. Así, por ejemplo, se relata que el cabo Pacheco, "un simple labrador castellano", ha llegado a la División Azul porque "con frecuencia los hombres que luchan en las trincheras llegan a un punto en que no saben hacer otra cosa que pelear" (Royo, 1956: 21). Así como es precisamente el personaje Turuta, "el único analfabeto de la División Azul”, quien es derrotado por las penalidades de la guerra y se automutila para ser repatriado, por lo que, pese a la piedad que sienten todos los compañeros por él, es condenado a muerte y ejecutado (Royo, 1956: 32, 154-159). En los dos casos, el autor enseña abiertamente que los divisionarios menos admirables forman parte de las clases sociales más bajas, algo perfectamente coherente con el ideario de Falange, extremadamente clasista y elitista (Albert, 2003: 246; Ellwood, 1984: 59; Rodríguez Puértolas, 2008: 46).
} 
anuncia haber descubierto su red clandestina y que va a proceder a aniquilarla. Como alega finalmente el protagonista,

yo no me puedo convertir en el denunciante o el verdugo de mi hermano y, por otra parte, tampoco puedo permitir que mi propia gente no haga nada para liquidar a esas fuerzas [...] Después de haber cumplido con el deber de advertir a Santiago, si no se quita de en medio y lo matan, yo me lavo las manos (Royo, 1956: 234-237).

El talante moral de José Luis, que le otorga también poder de persuasión y proselitismo, sobresale de todas formas en su relación con Lydia, una joven española de los niños de Rusia que al comienzo de la historia milita en el bando comunista y hace de espía para la organización de Santiago. Las muertes de su hijo y de Anna, su compañera y amiga desde la infancia, y la relación sentimental que surge con José Luis, hacen que Lydia empiece a dudar de esa fidelidad a la doctrina comunista que le había impuesto su propio padre. A raíz de esos acontecimientos, los ideales de Lydia se debilitan gradualmente, dándose cuenta de que "La teoría de la lucha de clases con la que ella había comulgado era la teoría del odio, de la muerte, del fratricidio sistemático" (Royo, 1956: 98), y renegando de todo en lo que había creído hasta ese momento, al nacerle "en el corazón un odio brutal contra todo, y de manera más concreta contra el comunismo, contra los rusos, contra Stalin” (Royo, 1956: 197).

La conciencia de haber servido a una doctrina nefasta y a un país que no es el suyo, además de la admiración y el amor creciente por José Luis, empujan a la chica a desvelarle al divisionario la verdadera identidad de Boris Protsenko. Finalmente, después de haber entregado al comisario político el mensaje en el que José Luis le previene contra el peligro, para redimirse Lydia pone en conocimiento de todos los planes de la resistencia a los mandos de la División Azul. Después de una despiadada lucha interior entre los principios que le había inculcado su padre y lo que parece un llamamiento espiritual hacia la patria olvidada y el idealismo propagado por el falangista José Luis, "su espíritu maltrecho se irguió como un tronco robusto lleno de savia mística y cristiana. La costra oscura y repugnante del materialismo marxista se le había desprendido de un golpe” (Royo, 1956: 260), y la mujer decide actuar favoreciendo al bando español.

La conversión de Lydia, finalmente, se manifiesta a través de una imagen de lo más poético, y claramente afiliada al entramado retórico del falangismo: "Las estrellas rojas de su firmamento comunista habían desaparecido por completo y en el cielo azul, recién liberado, titilaban luceros victoriosos. Una oleada de poesía mística inundó el corazón de la muchacha” (Royo, 1956: 263), quien consigue volver a España e, inmediatamente después, volver a Rusia como enfermera voluntaria.

Es legítimo afirmar, para concluir con el análisis de la figura de José Luis, que el protagonista de El soly la nieve (1956) expresa un tipo de heroicidad distinto al que se encontraba en ;Guerra! (1944), una heroicidad menos ardorosa, belicista y agresiva, sino más meditada, recta y noble, hundiendo las raíces en "su esencia moralizante, los valores que transmite, la capacidad que tiene de crear para el individuo una realidad trascendente, no negociable y superior a las demás" (Salas Díaz, 2010: 24). El arrojo exaltado que poseía en grado sumo Luis Pablos es sobradamente compensado por la experiencia y el recorrido vital de José Luis, quien ha asentado la fe y sinceridad de sus ideales en la fortaleza de la madurez. 
Pese a las primeras decepciones y embestidas del desencanto, el autor sigue propagando en El sol y la nieve (1956) su idealismo falangista, desposeyéndolo de su carga más violenta para ahondar en otro tipo de principios de ascendencia joseantoniana: el amor, el honor y la solidaridad. José Luis, permaneciendo dentro del horizonte del arquetipo del monje-soldado, se inclina más bien hacia el lado espiritual de ese binomio, de forma opuesta a Luis Pablos, quien en cambio reflejaba el carácter más combativo de la doctrina falangista.

\section{EL SEPULTURERO (1976): LA DERROTA DEL HÉROE DESENCANTADO}

Harto distinto es, finalmente, el protagonista de El Sepulturero (1976), Julián Rovira. Ante todo, hay que comentar que la historia relatada en esta obra no tiene lugar en el Frente del Este como las dos anteriores, sino que se ambienta en los años 70, a finales de la dictadura franquista, por lo que su estructura temporal es más compleja y desarrollada, al abarcar la vida del personaje principal desde su juventud hasta el tiempo de la narración. Su trama, entonces, no está centrada solamente en las vivencias de Julián Rovira en la Unión Soviética; y, sin embargo, es la trascendencia de esa experiencia en su vida lo que permite analizar esta novela en comparación con las dos anteriores.

Como José Luis, Julián Rovira también luchó tanto en la Guerra Civil como en la Unión Soviética, donde se distinguió por su índole heroica, al participar en "una de las páginas más bellas y espeluznantes de la historia del mundo, una página que hoy se estudia todavía en las academias militares [...] como ejemplo de limpio espíritu castrense" (Royo, 1976: 86), a saber: la operación de rescate de una guarnición alemana por parte de la Compañía de Esquiadores, en enero de 1942. En esa empresa, alrededor de doscientos divisionarios recorrieron más de 30 kilómetros sobre la superficie helada del lago Ilmen, con una temperatura entre los 50 y los 55 grados bajo cero, para atacar a un contingente ruso desde una posición inesperada y liberar a los aliados alemanes del cerco al que estaban sometidos. Al final de la operación, concluida de forma exitosa, quedarían ilesos tan solo doce soldados; y la mayoría de las bajas se debieron a la congelación (Royo, 1976: 84-88) ${ }^{12}$. Entre los afectados se encuentra Julián Rovira, a quien le amputan parte de una mano y le repatrían a España.

Siguiendo con la comparación con el personaje José Luis, el protagonista de El Sepulturero (1976) también es un hombre distinguido y culto, quien a la vuelta del frente se dedica a la carrera diplomática; asimismo, es un idealista, un falangista modélico cuya máxima aspiración vital es llevar a cabo la revolución nacionalsindicalista (Royo, 1976: 28-29). Pero su fidelidad al ideario falangista ya no tiene los mismos tintes épicos que antaño, puesto que El Sepulturero (1976) es claramente una novela perteneciente a la segunda etapa de la novelística divisionaria, la que está marcada por el desencanto. La coherencia de Julián Rovira, por lo tanto, se parece más a la del personaje Eugenio de El sol y la nieve (1956), quien se describía a sí mismo como "un sentimental estúpido, un romántico cursi, un imbécil", por creer todavía en la posibilidad de imponer su

\footnotetext{
${ }^{12}$ La acción de la Compañía de Esquiadores es uno de los vértices del heroísmo del discurso divisionario por como se presentó en su propaganda, y fue recogida en su novelística por diferentes autores (Blanco, 1954: 45-47; Gómez Tello, 1945: 145-151). Pese a la prácticamente nula utilidad militar y estratégica de la acción, la magnitud del sacrificio de los soldados españoles hizo que esta se convirtiera en uno de los episodios más mitificados y propagados del relato divisionario (Núñez Seixas, 2016: 174; Possi, 2017: 235).
} 
ideario en una España inmovilista donde seguían mandando los mismos de siempre (Royo, 1956: 81). Julián Rovira termina convirtiéndose en la encarnación cabal del desengaño de los falangistas que permanecieron fieles a las consignas originarias del movimiento a pesar del paso del tiempo y los cambios internos a la dictadura, además de ser expresión diáfana "de las últimas resistencias de los franquistas bunkerianos a desaparecer” (Rodríguez Puértolas, 2008: 717).

El heroísmo encarnado por Julián Rovira adquiere entonces una dimensión trágica que les era ajena a Luis Pablos y José Luis, sobre todo porque su heroicidad no está limitada a la etapa guerrera, sino que se extiende a lo largo de toda su vida, convirtiéndolo en un personaje cuya complejidad rebasa ampliamente la de los dos anteriores.

La lucha del protagonista de El Sepulturero (1976), pues, prosigue después de su vuelta a España, con el objetivo de afianzar la revolución falangista; pero es un combate que, desde el principio, se estrella contra un enemigo mortal de necesidad: el Sepulturero, un personaje antropomorfo alegoría de todo lo corrupto que Falange quería aniquilar, especialmente en relación con las derechas tradicionalistas, que se identificaban con "lo falso y aparencial [...] con lo viejo, raído, corroído y caduco, con lo utilitario y lo burocrático, y con sinónimo de decadencia, Estado viejo y capitalismo" (Carbajosa y Carbajosa, 2003: 115).

La aparición del Sepulturero, tanto en el panorama español como en la vida de Julián Rovira, es muy temprana, cuando ya en la posguerra civil "los mercaderes sembraban la corrupción en las fértiles praderas que había purificado la guerra” (Royo, 1976: 48). Mientras que, en el primer encuentro entre el protagonista y el Sepulturero, este último aparece con pinta de banquero y cavando una fosa, donde declara que va a enterrar "las flores, la juventud, las ilusiones, el amor, la caridad, los principios. [...] la revolución, la sangre, el sacrificio, las promesas, la dignidad, el honor. [...] la poesía, [e]l futuro y las banderas victoriosas" (Royo, 1976: $17)^{13}$.

La lucha de Julián Rovira contra el Sepulturero, aparte que en el plano simbólico, repercute también en su vida, y, especialmente en dos episodios: cuando, por su rectitud y su compromiso con los preceptos revolucionarios, denuncia a su protector por estraperlista y al embajador de Estados Unidos por apropiación indebida de dinero, arriesgando así su recién estrenada carrera diplomática (Royo, 1976: 94-97, 76-78)14. El informe con las acusaciones hacia el embajador no prospera, pese a lo irrefutable de las acusaciones; al revés, el que sale perjudicado de ese trance es Julián Rovira, quien es castigado con el traslado a Madrid (Royo, 1976: 113-115).

A la altura de los años 50, el asunto ocasiona indignación entre el círculo de tertulianos que frecuenta el personaje en la capital, donde se debate largamente acerca del llamado "chantaje de

\footnotetext{
${ }^{13}$ En el pasaje citado son evidentes algunos de los dogmas y las imágenes tópicas del idealismo falangista, además de los ecos del himno del Movimiento, el Cara al sol, manifestando de forma preclara valor simbólico tanto del personaje Sepulturero como de sus acciones.

${ }^{14}$ El embajador Fausto Lezcano, a quien Julián Rovira denuncia por sus trapicheos, es un hombre cínico y sagaz, emblema de la supervivencia del sistema en perjuicio de la nueva España, puesto que "El nuevo régimen, acosado por los cuatro costados al término de la II Guerra Mundial, había echado mano de aquellos viejos tiburones, cuyas mañas y resabios utilizaba sin recato, buscando así su salvación y consolidación. No se daba cuenta el nuevo régimen de que en realidad eran los viejos tiburones los que lo estaban utilizando a él para escalar nuevamente la cucaña de sus privilegios y sus inmoralidades" (Royo, 1976: 75).
} 
los garbanzos" del que ha sido víctima Julián, y la conclusión a la que llegan los hombres, todos ellos "románticos, soñadores, quiméricos" (Royo, 1976: 121), es que las malas prácticas son fruto de la infiltración del enemigo en sus filas. Aunque el desencanto compartido hace que algunos de ellos piensen, en realidad, que el enemigo son ellos mismos, al permitir que las cosas sigan por ese camino, otro personaje, Pancho Casares, les devuelve a todos a la realidad con su decepción, afirmando que la única solución posible sería quizá volver a tomar las armas, pero que él ya no cree en nada, por lo que desestima también esa posibilidad utópica (Royo, 1976: 119-120).

Sin embargo, mientras que, con el paso del tiempo, "Casi todos los muchachos de la época heroica, los más revolucionarios y ardorosos combatientes”, evolucionan hacia las posturas desilusionadas de Pancho Casares, inclinándose por "el nihilismo, los grandes negocios o la política profesional" (Royo, 1976: 220), Julián Rovira sigue tozudamente devoto a sus ideales y continúa con su lucha apasionada contra el Sepulturero y ese futuro cambiante en el que se derrumban los principios éticos y morales tradicionales, y en el que triunfan la mecanización, la deshumanización del hombre y el pragmatismo ególatra (Royo, 1976: 30-31).

El heroísmo que caracteriza a Julián Rovira se va definiendo, conforme avanza su trayectoria, como rotundamente distinto al de Luis Pablos y José Luis, que estaba limitado a sus epopeyas bélicas; en cambio, el protagonista de El Sepulturero (1976) adquiere un estatus heroico, en su dimensión trágica, por no desmentirse, por permanecer coherente a sí mismo pese a las adversidades externas, y de allí proviene su gloria (Savater, 2009: 153). No obstante, Julián Rovira se convierte a la vez en un personaje quijotesco, en un héroe abocado al fracaso, destinado por su propia voluntad enfermiza a luchar contra un imposible, eso es, un régimen que se ha burocratizado, corrompido y alejado irremediablemente de los ideales revolucionarios del falangismo. Para mayor inri, cuando ya en los años 70 es definitivamente expulsado de la carrera diplomática, "vuelve al redil de sus viejos camaradas y dice que quiere jugar a canicas con ellos para ganar rápidamente mucho dinero y hacer ahora, en serio, la revolución” (Royo, 1976: 148).

La suspicacia con la que le reciben sus antiguos compañeros, quienes finalmente se han beneficiado del sistema más o menos honradamente, y los engaños de los que es víctima por su ingenua y ciega confianza en unos ideales ahora ya periclitados y en cierto sentido peligrosos, terminan minando al personaje moral y psicológicamente ${ }^{15}$. La toma de conciencia de que "Nada de lo que había soñado y ambicionado en su juventud se había convertido en realidad: ni el amor,

\footnotetext{
${ }^{15}$ En una conversación con los amigos Pancho Casares y Tony Fernández, que tiene lugar poco antes del comienzo de la narración, Julián Rovira se explaya largamente acerca de las causas de la agonía del régimen, y las compendia en tres puntos: la liquidación de los viveros -el SEU y el Frente de Juventudes-; la corrupción; y la represalia contra esos incorruptibles que se resisten a la incorporación al sistema (Royo, 1976: 186-188). Mientras que Pancho Casares se acusa a sí mismo - por escéptico y corrupto- por cómo han evolucionado las cosas después de que España malograra la revolución falangista, Julián Rovira le echa la culpa al Sepulturero, eso es, al sistema mismo, que permitió el advenimiento de tecnócratas, capitalistas y estraperlistas corruptos, quienes "le chupan la sangre a España a la luz del día" (Royo, 1976: 183-184, 188) y convierten al mismo Franco en una víctima, en el "hombre que más ha sufrido sus viciosos ataques" (Royo, 1976: 184). Sin embargo, Julián Rovira todavía cree en la posibilidad de reformar el régimen, además de poderlo hacer él mismo, porque, como afirma, "yo soy Franco" (Royo, 1976: 189). A partir de ese momento, el desencanto del protagonista evoluciona rápidamente hacia la locura, y más evidentes se hacen las "síntomas de que su equilibrio mental no era perfecto" detectadas por Tony Fernández, quien además está convencido de que "Un hombre que luchaba de aquella manera desaforada contra la corriente, que se obstinaba tan sistemática y fieramente en hacerse daño a sí mismo, no podía estar cuerdo” (Royo, 1976: 190).
} 
ni la revolución, ni la victoria" (Royo, 1976: 16) ocasiona el último encontronazo con el Sepulturero, quien se hace burlas del personaje y le obliga a enfrentarse con esa realidad a la que Julián Rovira no quiere someterse, ese mundo donde él ya lo tiene todo perdido, donde solo es un hombre frustrado por el incumplimiento de sus propósitos, y donde el régimen por el que luchó y que quiso ardientemente mejorar se está hundiendo, devorado por el sistema cuya máxima expresión y alegoría es, precisamente, el Sepulturero (Royo, 1976: 252-254).

La última provocación del antagonista ontológico de Julián Rovira es contundente: despectivamente, le anuncia que la refundación del régimen "sólo podría ocurrir si hubiese alguien que hiciese algo grande. Pero no lo hay", dado que "los poquísimos insensatos como tú, que seguís resistiendo en los blocaos, carecéis de unidades de refresco" (Royo, 1976: 253-354). Y esto impulsa al personaje al borde de la locura y al cumplimiento de la insensata acción con la que se abre la novela: el secuestro del avión en el que está viajando para desviarlo rumbo a Pekín y así "irse con Mao Tse Tung, para ver si allí podía enderezar las cosas o, por lo menos, acomodarse en el seno de una sociedad que a él, desde la distancia, se le antojaba más justa y más humana" (Royo, 1976: 18).

La última, épica y desesperada hazaña de Julián Rovira en pos de la afirmación de sus ideales termina de forma denigrante con un engaño por parte del comandante del avión secuestrado. Después de haberle escuchado afirmar al protagonista que él es Francisco Franco Bahamonde, el comandante le convence de que el almirante Carrero Blanco en persona está esperando para que le firme un decreto, y el hombre que se presenta como Carrero Blanco consigue que Julián Rovira le entregue la pistola con la que amenazaba a la tripulación (Royo, 1976: 256-257), momento que decreta el final de la novela. El héroe desencantado y anacrónico, Julián Rovira, ha sido derrotado por el Sepulturero, por la locura que se ha apoderado de él y, en general, por el vacío social que se ha creado alrededor de su figura y que le corona como paradigma de los héroes contemporáneos, aquellos que "no encuentran sencillamente su puesto en ningún orden, pues aquello mismo por lo que luchan está muy lejos de satisfacerles. Su triunfo es su mayor derrota, el momento en que advierten lo inevitable de su derrota" (Savater, 2009: 164).

Pese al fracaso histórico y político, Julián Rovira triunfa moral e ideológicamente en base a los dogmas de la cosmovisión falangista, según la cual "Quien lucha generosamente sin reparar en sacrificios por una empresa histórica que le rebasa [...] es un hombre selecto" (Pradera, 2014: 258). El fracaso de Julián Rovira es el del autor Rodrigo Royo, a la vez que el de una entera generación de falangistas; la sensación de haber sido utilizados por parte de las élites tradicionalistas del franquismo, a fin de mantener el status quo (Ellwood, 1984: 138), se enquista en un desencanto que imbuye finalmente toda su visión del mundo, pero que no desacredita en absoluto el valor de la entrega al ideal y la nobleza de quien lo profesa. La derrota política e histórica de los falangistas radicales se presenta pues, quizá paradójicamente, como el triunfo de su superioridad moral, y por eso, en medio del derrumbe de su ideología y época, lo único que queda es la integridad del héroe, que termina siendo el solo tópico del falangismo originario no contaminado por críticas o revisiones dictadas por el cambio de la situación interna al régimen franquista. La rebelión del héroe contra el sistema desemboca en la locura, pero este logra salvar, en medio del desbarajuste final, lo más importante: la coherencia, el honor y el auténtico estilo de 
vida falangista, "sacrificado, [...] impetuoso, heroico, paciente, resistente, perseverante, orgulloso, [...] franco, limpio, firme, [...] incómodo..." (Carbajosa y Carbajosa, 2003: 116).

\section{CONCLUSIÓN}

En consecuencia, podemos afirmar que la trilogía divisionaria de Rodrigo Royo es emblemática de las transformaciones que se dan dentro de la novelística acerca de la División Azul escrita por los veteranos de guerra a su vuelta del Frente del Este. De hecho, publicándose las tres obras de Royo en 1944, 1956 y 1976, su producción narrativa bien ejemplifica el paso desde el idealismo exacerbado -que definía a las novelas dadas a la imprenta entre los años $40 \mathrm{y}$ los años 50- al desencanto más acusado, tópico de esas novelas escritas a partir de finales de los años 50. Como vimos, la obra ;Guerra! (1944) se puede adscribir a las novelas divisionarias idealistas; en cambio, la sucesiva El sol y la nieve (1956), pese a seguir fiel al ideario falangista originario, empieza a dar muestras del desencanto que afectó a los supervivientes de la guerra en la Unión Soviética, situándose pues en una fase intermedia dentro del proceso de desilusión creciente que experimentaron esos autores veteranos que, por su lealtad hacia los ideales profesados en la juventud, asistieron con desconcierto a los cambios internos al régimen franquista a partir del final de la Segunda Guerra Mundial. Finalmente, El Sepulturero (1976) se enmarca rotundamente dentro de la novelística divisionaria del desencanto, ofreciendo una actitud decepcionada y disconforme para con la evolución del régimen en lo que respecta, básicamente, a su desfascistización, su repliegue hacia políticas de corte tradicionalista, y su rechazo y silenciamiento de la experiencia divisionaria al lado de la Alemania nazi, de cara al contexto internacional surgido a raíz de la victoria aliada en la contienda mundial.

El paso del idealismo al desencanto se ejemplifica, en las obras analizadas de Rodrigo Royo, en los cambios que le atañen a la representación de sus tres protagonistas -Luis Pablos, José Luis y Julián Rovira-, pese a que la desilusión no supone un alejamiento de los ideales del falangismo joseantoniano, sino que conlleva más bien una honda decepción vital que agudiza la dimensión trágica del heroísmo de los personajes literarios.

Así, Luis Pablos de la novela ;Guerra! (1944) encarna plenamente al héroe falangista arquetípico, enseñando el camino de perfección que lleva al personaje desde una juventud aburguesada, abúlica e individualista hasta el ideal revolucionario y exaltado del monje-guerrero, haciendo hincapié en lo fundamental de la experiencia bélica y en la centralidad de las virtudes guerreras. Su muerte, el sacrificio extremo por el ideal, certifica finalmente la sinceridad y pureza de su heroísmo. El personaje José Luis de El sol y la nieve (1956), por el contrario, simboliza un tipo de héroe distinto al anterior, no solamente fundamentado en el ardor guerrero sino, sobre todo, en la madurez emocional e ideológica del personaje, lo que responde también al planteamiento más reflexivo e intimista de la segunda novela de Rodrigo Royo. Pese a los primeros síntomas de decepción del personaje, el idealismo falangista permanece íntegro, aunque se desprende de su faceta belicosa para profundizar en los valores más espirituales de la figura del monje-soldado, esto es, la solidaridad, el amor y la entrega a la causa en pos de la mejora de la comunidad. Finalmente, el protagonista de El Sepulturero (1976), Julián Rovira, es un héroe terminantemente trágico, que ha sido derrotado por el paso del tiempo y los cambios políticos en el seno del régimen franquista y que sin embargo sigue, aunque ahora ya anacrónicamente, 
propagando su fidelidad ideal y práctica a los caducos dogmas falangistas. La grandeza de su figura hunde las raíces precisamente en su derrota vital y en el desprecio que Julián Rovira demuestra hacia ella, desafiando al sistema corrupto contra el que lucha desaforadamente hasta ser vencido por la locura. Su fracaso frente al Sepulturero es, por un lado, el juicio histórico que condena concluyentemente al falangismo radical a su ocaso; y, por otro, es la victoria espiritual de quienes no se han traicionado a sí mismos para encontrar un acomodo hipócrita dentro de una sociedad cada vez más corrupta, asumiendo las consecuencias de su coherencia hasta los efectos más trágicos y funestos.

Por esto, las novelas divisionarias de Rodrigo Royo alumbran de forma preclara el proceso que llevó a una entera generación de falangistas radicales desde el más apasionado idealismo hasta el desencanto atormentado de la madurez, tanto a nivel ideológico como a nivel estético. Su narrativa es un elemento imprescindible para ahondar en el análisis y estudio de la novelística divisionaria en su conjunto, tanto la de la primera como la de la segunda etapa, al enmarcarse sus obras en ambas etapas y convirtiéndose en un paradigma de sus hitos, tópicos, y evolución y cambio de los mismos. 


\section{BIBLIOGRAFÍA}

AlberCA, Manuel (2007). El pacto ambiguo. De la novela autobiográfica a la autoficción. Madrid: Biblioteca Nueva.

AlBERT, Mechthild (2003). Vanguardistas de camisa azul. La trayectoria de los escritores Tomás Borrás, Felipe Ximénez de Sandoval, Samuel Ros y Antonio de Obregón entre 1925 y 1940. Madrid: Visor Libros.

BERNECKER, Walther L. (1998). "El debate sobre el régimen franquista: ¿Fascismo, autoritarismo, dictadura de modernización?”. MECHTHILD, Albert (ed.). Vencer no es convencer. Literatura e ideología del fascismo español. Frankfurt-Madrid: Vervuert-Iberoamericana: 29-49.

Biblia de Jerusalén (1998). Bilbao: Editorial Desclée de Brouwer.

Blanco, Juan Eugenio (1954). Rusia no es cuestión de un día... Estampas de la División Azul. Madrid: Publicaciones Españolas.

BÖCKER, Manfred (1998). "¿Nacionalsindicalismo o fascismo? El fascismo español de la Segunda república y su relación con los movimientos fascistas en el extranjero". MECHTHILD, Albert (ed.). Vencer no es convencer. Literatura e ideología del fascismo español. Frankfurt-Madrid: VervuertIberoamericana: 13-27.

Caballero Jurado, Carlos e IbÁÑez Hernández, Rafael (1989). Escritores en las trincheras. La División Azul en sus libros, publicaciones periódicas y filmografía (1941-1988). Madrid: Ediciones Barbarroja.

CAMPBELL, Joseph (2017). El héroe de las mil caras. Psicoanálisis del mito. Madrid: Fondo de Cultura Económica de España.

CANO BALLESTA, Juan (1994). "La utopía del "amanecer" y del "imperio" en la retórica falangista". Las estrategias de la imaginación. Utopias literarias y retórica política bajo el franquismo. Madrid: Siglo XXI de España Editores: 21-56.

Carbajosa, Mónica, Carbajosa, Pablo (2003). La corte literaria de José Antonio. La primera generación cultural de la Falange. Barcelona: Crítica.

Di FEBO, Giuliana (1991). "El “monje guerrero": identidad de género en los modelos franquistas durante la Guerra Civil". Las mujeres y la Guerra Civil Española. III Jornadas de estudios monográficos. Salamanca, octubre de 1989. Madrid: Instituto de la Mujer/Ministerio de Cultura/ Ministerio de Asuntos Sociales: 202-210.

ELLWOOD, Sheelagh (1984). Prietas las filas. Historia de Falange Española, 1933-1983. Barcelona: Editorial Crítica.

Gómez Tello, José Luis (1945). Canción de invierno en el Este. Crónicas de la División Azul. Barcelona: Luis de Caralt.

JESI, Furio (2015). Cultura di destra. Con tre inediti e un'intervista. Roma: nottetempo.

MAINER, José-Carlos (2008). "La retórica de la obviedad: ideología e intimidad en algunas novelas de guerra". La Corona hecha trizas (1930-1960). Una literatura en crisis. Barcelona: Editorial 
Crítica: $165-192$.

MARTín, Eutimio. "Falange y poesía”. Historia 16 III.30 (1978): 125-128.

NúÑEZ SEIXAS, Xosé Manoel. "Los vencedores vencidos: la peculiar memoria de la División Azul, 1945-2005”. Pasado y memoria 4 (2005): 83-113.

NúÑEZ SEIXAS, Xosé Manoel (2016). Camarada invierno. Experiencia y memoria de la División Azul (1941-1945). Barcelona: Crítica.

Paniagua, Eleuterio (1961). Los hombres se matan así. Madrid: Lorenzana.

Pemartín, Julián (1949). Teoría de la Falange. Madrid: Ediciones de la Sección Femenina.

Penella, Manuel (2006). La Falange Teórica. De José Antonio Primo de Rivera a Dionisio Ridruejo. Barcelona: Editorial Planeta.

PÉREZ BOWIE, José Antonio (1979). Muerte, ideología y lenguaje. Zamora: s/n.

PossI, Valeria. "Idealismo e imaginario falangista en las primeras novelas de la División Azul". Castilla. Estudios de literatura 8 (2017): 216-257.

PRADERA, Javier (2014). La mitología falangista (1933 a 1936). Madrid: Centro de Estudios Políticos y Constitucionales.

PRILL, Ulrich (1998). "Mitos y mitografía en la literatura fascista". Albert, Mechthild (ed.). Vencer no es convencer. Literatura e ideología del fascismo español. Frankfurt-Madrid: VervuertIberoamericana: 167-179.

Primo De Rivera, José Antonio (1939). "Discurso de la fundación de Falange Española". Obras completas. Tomo I. Discursos fundamentales y otros discursos de propaganda. Madrid: Ediciones F. E.: 13-26.

Primo DE RIVERA, José Antonio (1940). "Norma programática de la Falange”. Obras completas. Tomo III. Misión y revolución. Madrid: Ediciones F. E.: 93-102.

Rodríguez PuÉrtolas, Julio (2008). Historia de la literatura fascista española. Tres Cantos: Ediciones Akal.

RoYo, Rodrigo (1944). ¡Guerra! Historia de la vida de Luis Pablos. Madrid: Gráficas Ultra.

RoYo, Rodrigo (1956). El soly la nieve. Madrid: Gráficas Cíes.

RoYO, Rodrigo (1976). El Sepulturero. Madrid: Sedmay Ediciones.

Ruiz Ayúcar, Ángel (1976). La Rusia que yo conocí. Madrid: Fuerza Nueva Editorial.

RUIZ BAUTISTA, Eduardo (2005). Los señores del libro: propagandistas, censores y bibliotecarios en el primer franquismo (1939-1945). Gijón: Ediciones Trea.

SAlvador, Tomás (1954). División 250. Barcelona: Ediciones Domus.

Salas DíAZ, Miguel (2010). Mitos patrióticos. Apuntes sobre la construcción del nacionalismo español en la literatura del siglo XX. Valladolid: Universidad de Valladolid. Secretariado de Publicaciones e intercambio editorial. 
SAVATER, Fernando (2009). La tarea del héroe. Madrid: Editorial Ariel.

Trigo, Luisa. "El voto de la mujer. Opiniones de Primo de Rivera". La Voz (14 de febrero de1936): 1-5.

WAHNÓN, Sultana (1998). La estética literaria de la posguerra. Del fascismo a la vanguardia. Ámsterdam: Rodopi.

YDíGORAS, Carlos María (1984). Algunos no hemos muerto. Madrid: Editorial CYR.

Zunino, Pier Giorgio (2013). L'ideologia del fascismo. Miti, credenæe, valori. Bolonia: Il Mulino. 